\title{
Keratinocyte Carcinoma and Risk for Another Type of Cancer: Assessment of a Dose-response Relationship
}

\author{
ASHLEY WILSON ${ }^{1}$, JAMES SMALL $^{2}$, CATHERINE FLANAGAN $^{1}$, DAVID PERRY ${ }^{3}$, \\ RICHARD MARCHELL ${ }^{3}$, BRUCE THIERS ${ }^{3}$ and ANTHONY J. ALBERG ${ }^{1,2,4}$ \\ ${ }^{1}$ Hollings Cancer Center, Medical University of South Carolina, Charleston, SC, U.S.A.; \\ ${ }^{2}$ Department of Public Health Sciences, Medical University of South Carolina, Charleston, SC, U.S.A.; \\ ${ }^{3}$ Department of Dermatology and Dermatologic Surgery, \\ Medical University of South Carolina, Charleston, SC, U.S.A.; \\ ${ }^{4}$ Department of Epidemiology and Biostatistics, \\ University of South Carolina Arnold School of Public Health, Columbia, SC, U.S.A.
}

\begin{abstract}
Background/Aim: Keratinocyte carcinoma $(K C)$ is a marker of increased risk of other cancer types. To assess if this association exhibits a dose-response relationship, a casecontrol study was carried out. Patients and Methods: This was a clinic-based study of cases with KC plus another type of cancer matched by age, race (all Caucasian), sex and histologic type to controls with $K C$ only ( $n=48$ matched pairs). Results: Compared with the KC only group, those with KC plus another cancer had a mean number of lesions that were $43 \%, 35 \%$, and $41 \%$ greater for basal cell carcinoma (BCC), squamous cell carcinoma (SCC), and total $K C$, respectively. The odds ratio $(O R)$ of developing another type of cancer increased from 1.0 to $1.09(95 \%$ confidence interval $(C I)=0.23-5.13)$ to $2.12(95 \% C I=0.50-9.08)$ according to whether the patient had zero, one, or $\geq$ two BCC lesions; for $S C C$, the corresponding ORs were 1.0, $1.24(95 \% C I=0.48$ 3.24), and 1.39 (95\%CI=0.29-6.61). Conclusion: A doseresponse relationship seems to exist between the number of skin lesions and the risk of another type of cancer, but the lack of statistical significance weakens this evidence.
\end{abstract}

Keratinocyte carcinoma (KC), also referred to as nonmelanoma skin cancer, is almost certainly the most commonly diagnosed cancer in the world, but the lack of systematically collected data makes this difficult to

Correspondence to: Anthony J. Alberg, Ph.D., MPH, Department of Epidemiology and Biostatistics, University of South Carolina Arnold School of Public Health, 915 Greene Street, Columbia, SC 29208, U.S.A. Tel: +1 8037776220, e-mail: alberg@ mailbox.sc.edu

Key Words: Keratinocyte carcinoma, nonmelanoma skin cancer, case-control study, epidemiology, cancer risk, second primary cancers. demonstrate definitively (1). An extensive body of evidence has clearly shown that a personal history of $\mathrm{KC}$ is indicative of increased risk of other cancer types (2-6). This increase in the risk of a subsequent cancer other than $\mathrm{KC}$ is consistent for the two major histological types of $\mathrm{KC}$, basal cell carcinoma (BCC) and squamous cell carcinoma (SCC), is observed in both males and females, and applies to a broad spectrum of other types of cancer (2-6). Thus, KC may be a marker for a cancer-prone phenotype.

Even though the association between personal history of $\mathrm{KC}$ and increased risk for other malignancies is well supported by evidence, important questions about this association remain unanswered. One key question that has yet to be thoroughly addressed is whether the risk of other cancers is increased as the number of $\mathrm{KC}$ lesions increases, meaning that there is a dose-response relationship present. The importance of assessing whether a dose-response association exists is twofold: 1) within the framework of epidemiologic inferences, the presence of a dose-response relationship would further strengthen the evidence favoring an association between $\mathrm{KC}$ and risk of other cancers, and 2) it could have potential clinical implications related to risk stratification of patients. That is, if a history of many KC lesions confers a considerably higher risk for other cancers compared with a history of fewer $\mathrm{KC}$ lesions, perhaps enhanced cancer surveillance would be beneficial for patients with a history of many $\mathrm{KC}$ lesions but not for those with fewer $\mathrm{KC}$ lesions. Thus, the purpose of the present study was to address the following question: Does the risk of a subsequent cancer other than $\mathrm{KC}$ increase as the number of $\mathrm{KC}$ lesions increases?

\section{Patients and Methods}

This study was approved by the institutional review board of the Medical University of South Carolina (MUSC). This study was 
a clinic-based matched case-control study that included recruitment of two groups of patients: A group of $n=50$ participants with a history of both $\mathrm{KC}$ and another cancer and another group with $\mathrm{n}=50$ participants with a history of $\mathrm{KC}$ only. The two study groups were matched for sex, age, and $\mathrm{KC}$ histologic type. Possible combinations of $\mathrm{KC}$ histologic types were SCC only, BCC only, and both BCC and SCC. Missing data on the number of $\mathrm{KC}$ lesions necessitated exclusion of four participants. The final study population for this report included 48 matched pairs.

Participation was limited to non-Hispanic Caucasians between 30-80 years old who were able to speak and understand English. This study was limited to non-Hispanic Caucasians because the risk of $\mathrm{KC}$ is predominant within this group (5). Individuals who were prisoners, institutionalized, pregnant, or cognitively impaired were not eligible to participate in the study.

During 2013-2014, participants were recruited from MUSC dermatology clinics. Prior to their clinic appointment, eligible patients were mailed an information packet. The study coordinator then contacted patients by telephone to assess their interest and eligibility. An appointment was scheduled during the clinic visit for those eligible and interested in participating, during which participants completed an informed consent form, HIPPA authorization, medical release forms, and an interviewer-administered questionnaire. Patients were compensated for participating in the study.

Data from participants were collected via an intervieweradministered questionnaire as well as a medical record review. The questionnaire consisted of questions regarding socio-demographic factors, health status, comorbidities, skin cancer risk factors, risk factors for other types of cancer, and other lifestyle factors. Information obtained from medical records consisted of body mass index, comorbidities other than cancer, $\mathrm{KC}$ history with regard to histologic type, location, number of lesions, and other cancer history with regard to location, cancer stage, and treatment. Self-reported history of other types of cancer was confirmed via medical record review including linkage to the South Carolina Central Cancer Registry.

Medical record data were prioritized over self-reported information for measuring $\mathrm{KC}$ history because although selfreported patient information is relatively accurate concerning skin cancer diagnoses, the accuracy decreases with respect to specific details such as the number of skin cancers and the histologic type $(7,8)$. In instances where the medical record data were missing or lacked information on the patient's skin cancer history, the patient's self-reported history was used.

In the data analyses, the dose-response association was assessed for BCC, SCC and for the total KC combined. The mean number of $\mathrm{KC}$ lesions were compared between groups using a paired $t$-test Matched odds ratios and $95 \%$ confidence intervals were calculated using conditional logistic regression models to analyze the frequency of $\mathrm{KC}$ lesions between groups in relation to the risk of a type of cancer other than KC. $p$-Values for trend in these odds ratios were calculated via a Cochran-Mantel-Haenszel test by fitting a single variable within ordered categories in a conditional logistic regression model. Additional variables adjusted for were education, body mass index, and cigarette smoking because each is a crosscutting risk factor for many types of cancer. Further adding to its potential confounding role, cigarette smoking is associated with risky sun exposure behaviors even in those with a personal history of skin cancer (9).
Table I. Percentage distributions ${ }^{a}$ of demographic characteristics of patients with history of history of keratinocyte carcinoma (KC) plus another cancer and keratinocyte carcinoma only.

\begin{tabular}{|c|c|c|}
\hline Characteristic & $\begin{array}{l}\text { KC plus another } \\
\text { cancer }(n=48)\end{array}$ & $\begin{array}{c}\text { KC only } \\
(n=48)\end{array}$ \\
\hline Mean age & 68 years & 68 years \\
\hline \multicolumn{3}{|l|}{ Gender } \\
\hline Female & $35 \%$ & $35 \%$ \\
\hline Male & $65 \%$ & $65 \%$ \\
\hline \multicolumn{3}{|l|}{ Race/ethnicity } \\
\hline Non-Hispanic white & $100 \%$ & $100 \%$ \\
\hline \multicolumn{3}{|l|}{ Education } \\
\hline Less than college graduate & $31 \%$ & $31 \%$ \\
\hline College graduate or greater & $69 \%$ & $69 \%$ \\
\hline \multicolumn{3}{|l|}{ Smoking history } \\
\hline Never & $33 \%$ & $54 \%$ \\
\hline Former & $63 \%$ & $40 \%$ \\
\hline Current & $4 \%$ & $6 \%$ \\
\hline \multicolumn{3}{|l|}{ Self-reported health status } \\
\hline Poor or fair & $15 \%$ & $4 \%$ \\
\hline Good & $48 \%$ & $38 \%$ \\
\hline Very good or excellent & $38 \%$ & $58 \%$ \\
\hline BMI (mean) & $28 \mathrm{~kg} / \mathrm{m}^{2}$ & $27 \mathrm{~kg} / \mathrm{m}^{2}$ \\
\hline \multicolumn{3}{|l|}{ Reaction to an hour of sunlight ${ }^{b}$} \\
\hline Tan & $54 \%$ & $46 \%$ \\
\hline Sunburn & $46 \%$ & $54 \%$ \\
\hline \multicolumn{3}{|c|}{ Mean hours of daily sunlight: teens } \\
\hline $0-2$ & $17 \%$ & $13 \%$ \\
\hline $3-4$ & $33 \%$ & $44 \%$ \\
\hline $5-6$ & $29 \%$ & $23 \%$ \\
\hline$\geq 7$ & $21 \%$ & $21 \%$ \\
\hline \multicolumn{3}{|c|}{ Mean hours daily sunlight: last ten years } \\
\hline $0-2$ & $42 \%$ & $56 \%$ \\
\hline $3-4$ & $40 \%$ & $31 \%$ \\
\hline $5-6$ & $15 \%$ & $6 \%$ \\
\hline$\geq 7$ & $4 \%$ & $6 \%$ \\
\hline \multicolumn{3}{|l|}{ Personal KC histologic type } \\
\hline BCC only & $50 \%$ & $58 \%$ \\
\hline SCC only & $8 \%$ & $15 \%$ \\
\hline Both BCC and SCC & $42 \%$ & $27 \%$ \\
\hline
\end{tabular}

KC: Keratinocyte carcinoma; BCC: basal cell carcinoma; SCC: squamous cell carcinoma; BMI: body mass index. ${ }^{a}$ Frequencies may not add to exactly $100 \%$ due to rounding; bIf participant's survey response was "tan or darken with no sunburn" or "no change in skin color", they were categorized as "tan". If participant's survey response was "blistering sunburn", "sunburn without blisters", or "mild sunburn that becomes a tan", they were categorized as "burn".

\section{Results}

Due to the matched study design, the proportion of males and females was identical in the group with $\mathrm{KC}$ plus another type of cancer compared with the group with KC only (Table I). All but two matched pairs were within \pm 3 years of age with a mean age of 68 years in both study groups. In both groups, most patients had a personal history of BCC either alone or in combination with SCC; $92 \%$ in the group with 
Table II. Mean number of keratinocyte carcinoma lesions in patients with keratinocyte carcinoma plus another cancer compared with patients with keratinocyte carcinoma only.

\begin{tabular}{|c|c|c|c|c|}
\hline & $\begin{array}{l}\text { Keratinocyte carcinoma plus } \\
\text { another cancer }(n=48)\end{array}$ & $\begin{array}{l}\text { Keratinocyte carcinoma only } \\
\qquad(\mathrm{n}=48)\end{array}$ & Percentage difference ${ }^{a}$ & $p$-Value ${ }^{\mathrm{b}}$ \\
\hline Basal cell carcinoma & 3.50 & 2.44 & $+43 \%$ & 0.22 \\
\hline Squamous cell carcinoma & 1.27 & 0.94 & $+35 \%$ & 0.36 \\
\hline Total keratinocyte carcinoma & 4.77 & 3.38 & $+41 \%$ & 0.19 \\
\hline
\end{tabular}

aCalculated as

$$
\left[\frac{\text { mean lesions KC plus another cancer -mean lesions KC only }}{\text { mean lesions KC only }}\right] \times 100
$$

bPaired $t$-test.

Table III. Odds ratios (and 95\% confidence intervals) for the association between number of keratinocyte carcinoma lesions and risk of another type of cancer.

\begin{tabular}{|c|c|c|c|c|}
\hline & $\begin{array}{l}\text { KC plus another cancer } \\
\qquad(\mathrm{n}=48)\end{array}$ & $\begin{array}{c}\text { KC only } \\
(\mathrm{n}=48)\end{array}$ & $\begin{array}{l}\text { Matched OR } \\
(95 \% \mathrm{CI})\end{array}$ & $\begin{array}{l}\text { Adjusted matched } \\
\text { OR }(95 \% \mathrm{CI})^{\mathrm{a}}\end{array}$ \\
\hline \multicolumn{5}{|l|}{$\mathrm{BCC}$} \\
\hline 0 & $8.3 \%$ & $14.6 \%$ & 1.0 (referent) & 1.0 (referent) \\
\hline 1 & $41.7 \%$ & $52.1 \%$ & $1.29(0.35-4.75)$ & $1.09(0.23-5.13)$ \\
\hline$\geq 2$ & $50.0 \%$ & $33.3 \%$ & $2.62(0.67-10.26)$ & $2.12(0.50-9.08)$ \\
\hline $\begin{array}{l}p_{\text {trend }} \\
\text { SCC }\end{array}$ & & & 0.10 & 0.18 \\
\hline 0 & $50.0 \%$ & $58.3 \%$ & 1.0 (referent) & 1.0 (referent) \\
\hline 1 & $27.1 \%$ & $25.0 \%$ & $1.20(0.52-2.79)$ & $1.24(0.48-3.24)$ \\
\hline$\geq 2$ & $20.8 \%$ & $14.6 \%$ & $2.13(0.52-8.79)$ & $1.39(0.29-6.61)$ \\
\hline $\begin{array}{l}p_{\text {trend }} \\
\text { Total KC }\end{array}$ & & & 0.31 & 0.60 \\
\hline 1 & $51.1 \%$ & $27.7 \%$ & 1.0 (referent) & 1.0 (referent) \\
\hline 2 & $10.6 \%$ & $25.5 \%$ & $3.33(0.99-11.19)$ & $3.03(0.86-10.64)$ \\
\hline$\geq 3$ & $38.3 \%$ & $46.8 \%$ & $2.74(0.84-8.80)$ & $2.15(0.62-7.47)$ \\
\hline$p_{\text {trend }}$ & & & 0.07 & 0.18 \\
\hline
\end{tabular}

aAdjusted for education, BMI, and smoking. KC: Keratinocyte carcinoma; BCC: basal cell carcinoma; SCC: squamous cell carcinoma; OR: odds ratio; $\mathrm{CI}$ : confidence interval.

KC plus another cancer compared with $85 \%$ in those with KC only (Table I).

Compared with the group with $\mathrm{KC}$ only, the mean number of $\mathrm{KC}$ lesions was increased in those with $\mathrm{KC}$ plus another cancer by $43 \%$ for BCC $(p=0.22), 35 \%$ for SCC $(p=0.36)$, and $41 \%$ for total KC $(p=0.19)$ (Table II). None of these differences were statistically significant.

In the odds ratio analysis, a pattern of association consistent with a dose-response trend was observed for BCC and SCC, although none of the trends were statistically significant (Table III). For BCC, the odds ratio of developing another type of cancer was increased from 1.0 (referent) to 1.29 $(95 \% \mathrm{CI}=0.35-4.75)$ to $2.62(95 \% \mathrm{CI}=0.67-10.26)$ according to whether the patient had zero, one, or $\geq$ two BCC lesions ( $p$ for-trend=0.10). For SCC, the odds ratio of developing another type of cancer increased from 1.0 (referent), to 1.20
(95\% CI $=0.52-2.79)$, to $2.13(95 \% \mathrm{CI}=0.52-8.79)$ according to whether the patient had zero, one, or $\geq$ two SCC lesions ( $p$-fortrend $=0.31$ ). For total KC there was not a monotonic trend with odds ratios of 1.0 (referent), 3.33 (95\% CI=0.99-16.84), and $2.74(95 \% \mathrm{CI}=0.84-8.80)$ for the categories of 1,2 , and $\geq 3$ lesions, respectively ( $p$-for-trend=0.07). Upon further adjustment for body mass index (BMI), education, and smoking, the pattern of the odds ratios continued to be consistent with a dose-response trend for BCC and SCC, although the associations were slightly weakened (Table III).

\section{Discussion}

A case-control study was carried out to determine if the association between $\mathrm{KC}$ and risk of malignancies other than $\mathrm{KC}$ was consistent with a dose-response trend, i.e., if the risk 
of types of cancer other than $\mathrm{KC}$ increases with an increase in frequency of $\mathrm{KC}$ lesions. The results of the present study consistently showed that the mean number of $\mathrm{KC}$ lesions was higher in those with $\mathrm{KC}$ plus another cancer compared with those with a personal history of KC only. Similarly, for BCC and SCC, monotonic trends in the odds ratios were observed showing increased risk of cancers other than KC with increased number of $\mathrm{KC}$ lesions. This pattern of associations provides evidence to support the presence of a dose-response trend, but this evidence is weakened by the fact that none of these associations were statistically significant.

All prior evidence on this topic has focused solely on BCC. To date, the major study of this topic was a casecontrol retrospective review using the Truven MarketScan insurance claims database comprised of approximately 124,000 patients with BCC (10). Compared with those with no personal history of BCC, the age- and sex-adjusted ORs for the risk of other malignancies were $1.61(95 \% \mathrm{CI}=1.58$ $1.65)$ for one $\mathrm{BCC}, 3.12(95 \% \mathrm{CI}=2.98-3.26)$ for $\geq 6 \mathrm{BCCs}$, and $4.15(95 \% \mathrm{CI}=3.79-4.53)$ for $\geq 12 \mathrm{BCCs}$ (the latter two categories were apparently not mutually exclusive) (10). Three additional studies added limited information because assessing for the presence of a dose-response trend was not the central line of inquiry. Of these three studies, two observed a trend of non-significant increased risk of malignancies with more BCCs $(11,12)$, whereas one study observed a statistically significant reduced risk for other cancers with a history of multiple BCCs compared to one (13). Overall, the prior evidence supports the presence of a dose-response association with greater number of BCCs associated with increased risk of other malignancies.

Against this backdrop, the results of the present study provide complementary evidence to further support the presence of a dose-response trend with $\mathrm{BCCs}$ and raise the notion that a dose-response trend may also be true for SCC. Strengths of the present investigation lie in studying both SCC and BCC in the context of a case-control study that was well designed to assess this question, with matching by age, sex, and histologic type of $\mathrm{KC}$ and with further adjustments for some major cancer risk factors. A limitation of the present study was the small sample size. Thus, despite observing a pattern of association consistent with a dose-response trend, the resulting lack of statistical precision led to results that were not statistically significant. The results of the present study were compatible with the presence of a dose-response trend for $\mathrm{BCC}$ that supports prior evidence, and the results further hint that a dose-response trend may also exist for SCC. Additional studies on this topic will help to further refine understanding of this association. This is an important line of inquiry, as it holds promise for leading to a better understanding of the link between $\mathrm{KC}$ and the risk of other malignancies. Further, this question has implications for clarifying the potential for translating this information into the clinical setting, emphasizing not only the importance of continued skin cancer surveillance (14), but also the potential use of multiple BCC and/or SCC lesions for purposes of risk stratification to carry out surveillance for non-cutaneous malignancies.

\section{Conflicts of Interest}

The Authors have no conflicts of interest to declare regarding this study.

\section{Authors' Contributions}

Ashley Wilson: drafted manuscript; manuscript revisions; James Small: data cleaning and data analyses; manuscript review and revisions; Catherine Flanagan: study implementation, including patient recruitment, data collection, data management; manuscript review and revisions; David Perry: assisted with medical record review; manuscript review and revisions; Richard Marchell: assisted with patient recruitment and clinical implementation; manuscript review and revisions. Bruce Thiers: securing funding, oversight of study design and study implementation; manuscript review and revisions; Anthony J. Alberg: securing funding, oversight of study design, study implementation, data analysis and interpretation; drafting and revising the manuscript.

\section{Acknowledgements}

This study was supported by the funding from CTSA NIH Grant UL1 TR000062 to the Medical University of South Carolina, from National Cancer Institute Cancer Center Support Grant (P30 CA38313) to the Hollings Cancer Center, Medical University of South Carolina, and funds from the Department of Dermatology and Dermatologic Surgery, Medical University of South Carolina.

\section{References}

1 Lomas A, Leonardi-Bee $\mathrm{J}$ and Bath-Hextall F: A systematic review of worldwide incidence of nonmelanoma skin cancer. $\mathrm{Br}$ J Dermatol 166(5): 1069-1080, 2012. PMID: 22251204. DOI: 10.1111/j.1365-2133.2012.10830.x

2 Alberg AJ and Fischer AH: Is a personal history of nonmelanoma skin cancer associated with increased or decreased risk of other cancers? Cancer Epidemiol Biomarker Prev 23(3): 433-436, 2014. PMID: 24609852. DOI: 10.1158/1055-9965.EPI-13-1309

3 Chen J, Ruczinski I, Jorgensen TJ, Yenokyan G, Yao Y, Alani R, Liégeois NJ, Hoffman SC, Hoffman-Bolton J, Strickland PT, Helzlsouer KJ and Alberg AJ: Nonmelanoma skin cancer and risk for subsequent malignancy. J Natl Cancer Inst 100(17): 1215-1222, 2008. PMID: 18728282. DOI: 10.1093/jnci/djn260

4 Ong EL, Goldacre R, Hoang U, Sinclair R and Goldacre M: Subsequent primary malignancies in patients with nonmelanoma skin cancer in England: a national record linkage study. Cancer Epidemiol Biomarker Prev 23(7): 490-498, 2014. PMID: 24769755. DOI: 10.1158/1055-9965.EPI-14-0355

5 Small J, Barton V, Peterson B and Alberg AJ: Keratinocyte carcinoma as a marker of a high cancer risk phenotype. Adv Cancer Res 130: 257-291, 2016. PMID: 27037755. DOI: 10.1016/bs.acr.2016.01.003 
6 Wheless L, Black J and Alberg AJ: Nonmelanoma skin cancer and the risk of second primary cancers: A systematic review. Cancer Epidemiol Biomarker Prev 19(7): 1686-1695, 2010 PMID: 20570907. DOI: 10.1158/1055-9965.EPI-10-0243

7 Holm AS and Wulf HC: Self-reported skin cancer is unreliable. Eur J Epidemiol 30(2): 159-162, 2015. PMID: 25600298. DOI: 10.1007/s10654-015-9992-x

8. Ming ME, Levy RM, Hoffstad OJ, Filip, J, Gimotty PA and Margolis DJ: Validity of patient self-reported history of skin cancer. Arch Dermatol 140(6): 730-735, 2004. PMID: 15210466.

9 Falk M, Faresjö A and Faresjö T: Sun exposure habits and health risk-related behaviours among individuals with previous history of skin cancer. Anticancer Res 33(2): 631-638, 2013. PMID: 23393359.

10 Cho HG, Kuo KY, Li S, Bailey I, Aasi S, Chang ALS, Oro AE, Tang JY and Sarin KY: Frequent basal cell cancer development is a clinical marker for inherited cancer susceptibility. JCI Insight 3(15): e122744, 2018. PMID: 30089731. DOI: 10.1172/ jci.insight.122744
11 Karagas MR, Greenberg ER, Mott LA, Baron JA and Ernster VL: Occurrence of other cancers among patients with prior basal cell and squamous cell skin cancer. Cancer Epidemiol Biomarkers Prev 7(2): 157-161, 1998. PMID: 9488591.

12 Rees JR, Zens MS, Gui J, Celaya MO, Riddle BL and Karagas MR: Non-melanoma skin cancer and subsequent cancer risk. Plos ONE 9(6): e99674, 2014. PMID: 24937304. DOI: 10.1371/journal.pone.0099674

13 Frisch M, Hjalgrim H, Olsen JH and Melbye M: Risk for subsequent cancer after diagnosis of basal-cell carcinoma. Ann Intern Med 125(10): 815-821, 1996. PMID: 8928988.

14 Seebode C, Lehmann J and Emmert S: Photocarcinogenesis and skin cancer prevention strategies. Anticancer Res 36(3): 13711378, 2016. PMID: 26977038. 